\title{
ODÉ KAYODÊ: AS PALAVRAS DE MÃE STELLA ECOAM NO TEMPO PERPETUANDO A FORÇA DAS MULHERES DE AXÉ
}

\author{
João Augusto dos Reis Neto ${ }^{1}$ \\ DOI 10.26512/revistacalundu.v4i1.30794
}

Este texto é antes de qualquer coisa um louvor à ancestralidade, sobretudo àquelas que vieram antes de nós, úteros sagrados dos quais somos filhos ancestrais. Por isso saudamos a força criadora de todas as mulheres, todas as Yabás, todas as mães ancestrais que nos geraram, todos os seios que nos nutriram e todas as mãos que nos acolheram. Mojubá!

Por isso também ele é um louvor à memória de Mãe Stella de Oxóssi, mãe pela qual louvamos todas as outras que fizeram brotar na espiral do tempo nossas existências. Assim, escrevo estas palavras para que possamos celebrar a potência da força feminina na construção e manutenção do candomblé no Brasil, e a vida e a história de Mãe Stella de Oxóssi.

Maria Stella de Azevedo Santos, baiana, bisneta de africanos, nasceu em 02 de maio de 1925, foi a quinta Ialorixá do Ilê Axé Opô Afonjá em Salvador (BA) e esteve à frente do terreiro do Afonjá por quarenta e dois anos. Nascida em uma família descendente de africanos, Stella sempre possuiu uma boa relação com o candomblé da Bahia. Stella perdeu a mãe muito cedo, ficando órfã e a tia, que também era conhecida como Dona Menininha, criou Stella como filha. Dona Menininha era amiga íntima de Mãe Menininha do Gantois. Os tios eram todos do Gantois, inclusive Dona Menininha tinha o posto de Arobá (cargo semelhante ao de Ekedi) no axé do Gantois e Stella estava prestes a ser iniciada ali também, entretanto não foi essa a vontade de Oxóssi.

Por vontade do Orixá, Mãe Menininha não conseguiu atender Stella quando ela foi levada para que se começasse a discutir a sua iniciação e Dona Menininha, sua tia, a levou até Mãe Aninha, Obá Biyi, então Ialorixá do Opô Afonjá. Dona Menininha era afilhada de Mãe Aninha e lá no Afonjá possuía o posto de Sobalóju (posto referente ao

\footnotetext{
${ }^{1}$ Mestre em Educação pela Universidade Federal de São João del Rei (PPEDU - UFSJ), licenciado em Biologia pela Universidade Federal de Lavras (UFLA). Integrante do Grupo de pesquisa "Laroyê: Culturas Infantis e Pedagogias Descolonizadoras" (UFLA) e da Rede Latino-americana em Educação, Cinema e audiovisual - Rede Kino (MG). Revisor do periódico "REDE - Revista Diálogos em Educação". E-mail: joaoaugusto.reis@gmail.com
} 
quarto de Xangô; cargo de grande confiança na casa de axé), o que significa que a família de Stella tinha uma boa relação com o Afonjá. Sobre este episódio, no documentário “Perfil”, realizada pela TV UFBA (2015), Mãe Stella nos conta:

Acredito muito no que nós chamamos de destino, nas coisas traçadas pelo infinito, pelo céu. E, apesar da minha família ser muito amiga do Gantois, nós somos consideradas como parentas (...), minha tia era muito amiga de Mãe Menininha, tanto que se tratavam como xará. Mas na hora da iniciação já é diferente, a coisa espiritual é diferente, o traçado espiritual é diferente de nossa vontade física. Eu cheguei aqui (no Afonjá) e acho que o orixá já estava me esperando, eu fui chegando e fui tomando conta do meu pedaço direitinho e fiquei aqui com o cargo que me deram no axé (...).

Na ocasião Mãe Aninha colocou a então menina Stella aos cuidados de Mãe Senhora, que nesta altura era Ossi Dagã (um posto) do Afonjá. Um ano depois, em 1939, voltava Stella ao Opô Afonjá e no dia 12 de setembro, aos quatorze anos de idade Stella foi iniciada por Mãe Senhora, que nesta altura já reinava como Ialorixá sucedendo Mãe Aninha. Na iniciação recebeu o orunkó (nome dado pelo orixá ao iniciado na tradição Ketu) de Odé Kayodê que significa "o caçador que traz alegrias", nome que, sem sombra de dúvida, define Mãe Stella. Conforme nos conta Campos (2003, p. 39), Mãe Stella foi uma típica filha de Oxóssi, e mais: "é o ofá (arco e flecha) de Oxóssi, inteiro, forte e estável, e ao mesmo tempo, flexível, sempre pronto a disparar a seta". Como uma boa filha do caçador ela sempre foi íntima do silêncio, afeita à observação, ao mesmo tempo que era cheia de vida, presença e alegria, características inerentes às mulheres de axé.

Mãe Stella dedicou grande parte de sua vida aos cuidados do outro se tornando enfermeira sanitarista, por volta dos dezesseis anos, pela escola de medicina da Bahia (atual Faculdade de Medicina da Universidade Federal da Bahia). Como enfermeira Mãe Stella se dedicou a cuidar do povo baiano por longos anos, até sua aposentadoria, próximo à sua ascensão ao trono do Afonjá. Aos vinte anos de idade Mãe Stella recebe das mãos de Mãe Senhora o cargo de Kolabá, a mulher que toma conta das coisas de Xangô, e tinha uma relação muito próxima com sua mãe de santo. Mãe Stella, uma filha dileta de Mãe Senhora, aos poucos foi conquistando seu lugar na religião e se preparando para ser a sacerdotisa que viria a ser. Nas palavras dela:

Depois de sete anos a gente torna-se adulto no axé, então já tem direitos, já tem obrigações a cumprir, responsabilidades dentro do axé. 
Nessa hora já uma iniciação, ajuda o outro a fazer, toma cuidado em ensinamentos e tudo mais. Aí eu fui entrando aí. Eu acho que minha mãe de santo descobriu que eu podia fazer essas coisas, então ela me chamava pra determinadas coisas até que me deu esse cargo de Kolabá, onde eu tomava conta das coisas de Xangô, também. Ainda criança, com dezenove, vinte anos, por aí. Daí fui ficando até que minha mãe faleceu. Aí veio outra mãe de santo (Mãe Ondina), eu fiquei aqui ajudando, como filha, até que ela também faleceu e eu fiquei sendo a mãe de santo da casa (MÃE STELLA, no documentário "Perfil", 2015).

Em 1976, Maria Stella, aos cinquenta e um anos de idade, é escolhida por Xangô - orixá patrono do Ilê Axé Opô Afonjá - para suceder Mãe Ondina de Oxalá tornandose então Ialorixá Stella de Oxóssi, Odé Kayodê. Na ocasião, o jogo de búzios que anunciou a sucessão de Mãe Ondina foi feito pelo conhecido e respeitado Professor Agenor Miranda. Em uma entrevista concedida ao Babalorixá Márcio de Jagun (do Instituto Ori - RJ) Mãe Stella conta que quando recebeu a notícia que seria a próxima Ialorixá do Afonjá ficou em choque, todavia, confiou na força dos orixás, principalmente Oxóssi, seu pai. Assim foi por quase meio século durante todo o seu matriarcado.

Em 1981, de acordo com Campos (2003), já como Ialorixá Mãe Stella visita a cidade de Oshogbo na Nigéria onde conhece alguns templos e casas de orixás. Conta-se que a voz de Mãe Stella ao entoar cânticos para Oxum (senhora da cidade de Oshogbo) fundia-se às dos demais, rompendo a barreira linguística e celebrando a ancestralidade que une as duas bandas do Atlântico. Nada mais simbólico que este encontro na terra de Oxum, senhora da fertilidade, do útero e da continuidade da vida. Oxum que também é o orixá de Mãe Senhora, mãe de santo de Mãe Stella. Encontros traçados pelo infinito no destino da Ialorixá. Desta viagem Mãe Stella traz a inspiração para a criação de um museu contando a história do Afonjá, que se mantém até hoje na roça de São Gonçalo, onde fica o terreiro.

Mãe Stella, nesta altura já era uma notória intelectual, encabeçou também uma espécie de "manifesto de libertação do candomblé" no qual ela, acompanhada de outras Ialorixás e representantes dos terreiros da Bahia, pediam a libertação do candomblé do sincretismo católico. Em 1986, em Nova York, Mãe Stella fala sobre a necessidade de o candomblé sair debaixo das asas da Igreja, buscando a superação do sincretismo religioso. Ela reconhecia o papel dele na sociedade escravista, mas defendia que não era mais necessário isto naquele momento. Sua fala durante a "III Conferência Mundial de 
Tradição dos Orixás e Cultura" repercutiu no mundo todo, sendo um marco na história do candomblé brasileiro. Um verdadeiro divisor de águas para o candomblé.

Mãe Stella foi a quinta Ialorixá do Afonjá, de 1976 a 2018 quando faleceu aos noventa e três anos. Seu matriarcado se encerrou depois de quase cinquenta anos à frente do Afonjá, o mais longo da história do Axé e foi marcado por importantes realizações. Podemos considerar que o matriarcado de Mãe Stella de Oxóssi, por inúmeras razões, representou uma nova era para o candomblé do Brasil, marcando profundamente a história do povo de axé e do próprio Brasil.

Sua trajetória foi marcada pela inovação, característica marcante do orixá Oxóssi para o qual fora iniciada. Oxóssi, na visão do candomblé Ketu, é o senhor da comunidade, o caçador, orixá da provisão, aquele que traz o alimento para nossa mesa, que traz o axé para as casas. Oxóssi também está ligado à cultura, à arte, à expansão dos limites da própria existência humana. Assim, a metáfora da caça se relaciona com a busca do conhecimento; Oxóssi é aquele que busca trazer o novo, aprender para ensinar, expandir. Oxóssi como um grande e habilidoso caçador é aquele responsável por buscar a novidade. Mãe Stella foi a boa e certeira flecha retesada no ofá (instrumento de caça; um arco de uma flecha só) do caçador para promover a expansão e o progresso de seu próprio povo.

Mãe Stella sem dúvida trazia em si a essência do caçador. Uma mulher visionária, fruto do seu tempo, corajosa e com o olhar firme no e para o progresso. Dentre as suas grandes realizações pode-se destacar sua destreza com a palavra. Como uma verdadeira griot Mãe Stella conta-nos, pela palavra oral, da história de seus ancestrais, de suas tradições, "presentifica" os ancestrais, rompe a barreira da vida e da morte, traço fundamental da cosmovisão nagô.

No documentário "Meu tempo é agora" (2010) ela nos presenteia com a sua palavra contando-nos a história do Opô Afonjá. As palavras de Mãe Stella nos levam quase que em um transe para o colo de Mãe Aninha, fundadora e primeira Ialorixá do Opô Afonjá. O tempo, que na visão nagô é circular, torna-se vivo, revive a memória de Mãe Aninha, ao passo que atualiza, torna contemporânea a essência dos orixás e do povo de santo. A tradição oral é a maior características das culturas africanas e foi por meio dela que nossos ancestrais puderam manter e recriar suas tradições aqui do outro lado do Atlântico na diáspora africana. Nesse sentido, é possível afirmar que a tradição religiosa afro-brasileira está fundamentada na oralidade, como nos conta Prandi (2000). Além disso, a palavra oral é sagrada pois é por ela que circula o axé, assim ela é 
fundamental na tradição dos candomblés do Brasil em seus processos educativos, na educação do axé.

Mãe Stella foi sem dúvida uma griot, aquela que pela oralidade transmitiu o axé, ensinou, expandiu com o seu povo, seus filhos. Entretanto, uma marca importante de sua história foi sua relação com a palavra escrita. No documentário "Perfil" (2015), produzido pela UFBA, ela conta que "toda vida" gostou de escrever e que não era raro se pegar fazendo anotações sobre seus afazeres como filha de santo e depois como líder do Afonjá. Mãe Stella conta que era compreensível também que muitas pessoas se apegassem apenas à oralidade tendo em vista que candomblé era uma religião de pessoas escravizadas e analfabetas.

Em uma entrevista concedida ao Babalorixá Márcio de Jagun (do Instituo Ori RJ) a Ialorixá conta que até a escrita do primeiro livro (em 1988) ela guardava uma certa resistência quanto à palavra escrita no candomblé, quanto à presença de livros sobre a tradição religiosa. Contudo, com o tempo Mãe Stella reconheceu a necessidade da presença de obras que contassem do candomblé, do povo de santo, segundo as suas próprias visões e vivências. Além disso, nas palavras dela "a oralidade é fundamental, mas o que não se registra o tempo leva”. Diante disso Mãe Stella começa a escrever.

A Ialorixá foi pioneira em publicar livros que contavam de suas tradições, sua cultura e religião. Fato que muitos consideraram estranho à época e criticaram, no entanto, Mãe Stella reafirmou sua força e continuou escrevendo ao longo de toda a sua vida. Sua estreia na literatura foi em 1988, em pareceria com Cléo Martins, quando escreve o livro "E dai aconteceu o encanto”, uma narrativa memorialística sobre as origens do Ilê Axé Opô Afonjá e das biografias das primeiras Ialorixás. Mãe Aninha, fundadora do Afonjá, é sempre lembrada com ternura nas palavras de Mãe Stella e serviu de referência para o matriarcado de Mãe Stella. Desde então ela assumiu o compromisso de falar de si, do seu povo e para o seu povo também por meio da palavra escrita. A Ialorixá-escritora passa a falar sobre o candomblé, sobre a cultura negra, de outro modo, por outra visão, desde dentro, uma vez que o que se lia sobre o povo de santo estava impregnado de racismo e preconceito.

Em 1993, Mãe Stella escreve seu segundo livro "Meu tempo é agora”, onde consagra-se definitivamente como escritora, este era seu primeiro livro individual. Sobre esta obra ela conta, ainda na entrevista ao Babalorixá Márcio de Jagun, que este livro foi uma resposta "às conversas mal feitas" defendendo o que ela chama de "seu tempo". Foi uma resposta às muitas conversas de comparação de Mãe Stella com suas 
predecessoras, nas quais muitos diziam "no tempo de Mãe Senhora, Mãe Aninha, não era assim", daí o título "Meu tempo é agora". A mensagem ali era de que ela era dona de seu destino e do que fazia enquanto Ialorixá no Afonjá; era uma espécie de manual sobre o candomblé do Afonjá, isso tudo sem revelar os segredos do candomblé. Nesta obra estava contida a leitura de uma Ialorixá sobre sua própria cultura, religião, vivência, identidade, prática e sobre "seu tempo", sobre a contemporaneidade da religião dos orixás. Era também, em resposta a tantas obras preconceituosas e racistas, uma visão contada desde dentro do candomblé.

Desde 1988 até sua morte Mãe Stella escreveu mais seis livros, dentre eles crônicas, contos, provérbios e até um infantil, "Epé Laiyê - terra viva" (2009). Seu amor pelas letras também a levou a construção de uma biblioteca no Afonjá e depois a criação de uma biblioteca itinerante, montada em um ônibus que circulava pela cidade de Salvador oferecendo leitura ao povo soteropolitano. Os livros da biblioteca tratavam de cultura geral, clássicos da literatura brasileira e um robusto acervo de literatura afrobrasileira e africana. Além disso, Mãe Stella escrevia quinzenalmente uma coluna no jornal baiano "A tarde" onde refletia sobre a vida, sobre o nosso mundo e o nosso tempo desde seu olhar de Ialorixá-escritora.

Mãe Stella também reafirmou seu compromisso preservando e dando continuidade ao sonho de Mãe Aninha de que seus filhos e netos pudessem estudar. Por isso, em 1986, a então creche "Mini Comunidade Obá Biyi”, torna-se escola atendendo crianças de $1^{\mathrm{a}}$ a $4^{\mathrm{a}}$ série. Em 1998 a escola é municipalizada e passa a se chamar "Escola Municipal Eugênia Anna dos Santos", atendendo aos primeiros anos do ensino fundamental, com a missão de resgatar a identidade e a cultura afro-brasileira de seus educandos. Tal feito revela que Mãe Stella era também uma visionária comprometida com a promessa de Mãe Aninha em fazer dos filhos de Xangô, do Afonjá, “doutores”. E isso não significava somente um título, mas uma superação da própria condição de "objeto de estudo"; o reconhecimento de sujeitos produtores de saberes e culturas. Foi sob a regência de Mãe Stella que grande parte da história do Afonjá se concretizou.

Mãe Stella foi uma distinta intelectual que inovou o olhar sobre as religiões de matriz africana, escrevendo sobre elas, o que a levou ser reconhecida em espaços nunca antes ocupado por mulheres negras, ou Ialorixás. Engajada na luta pelos direitos e da cultura do povo negro, Mãe Stella conquistou inúmeros títulos, e honrarias como a Comenda Maria Quitéria, da prefeitura de Salvador, e o título de Doutor Honoris Causa da Universidade Federal da Bahia em 2005 e da Universidade do Estado da Bahia em 
2009. Em 2013, Mãe Stella foi eleita por unanimidade a ocupar a cadeira de número 33 na Academia Baiana de Letras cujo patrono é o poeta Castro Alves. Muniz Sodré (2014), nos conta que "Mãe Stella, dentro da tradição das ialaxés do Opô Afonjá, é uma intelectual orgânica da comunidade litúrgica, dando especial atenção a trabalhos acadêmicos que digam respeito ao culto, dialogando frequentemente com escritores, artistas e jornalistas".

Mãe Stella foi (e continua sendo, pela lógica da ancestralidade) uma figura de destaque na luta do povo de santo, do povo negro, na constituição de nossas identidades. É sem dúvida uma mulher que faz ecoar no tempo suas palavras, seu pensamento orientando-nos e fazendo pensar no candomblé como uma construção histórica além da função religiosa. O candomblé é um espaço de educação e Mãe Stella sempre o soube, por isso seu compromisso em sempre educar seus filhos também ética e politicamente.

Mãe Stella, uma mulher negra, em sua história e escrita rompe com uma tradição racista e eurocêntrica que durante séculos vinha reificando os sujeitos negros, suas histórias e "folclorizando" suas práticas, vivências religiosas e culturais. Ela, na tradição de inúmeras outras mulheres negras, mulheres de axé, surge como resistência à narrativa unívoca contada pelo colonizador branco sobre os povos negros e sobre sua fé. Mãe Stella, acompanhada de muitas outras, tira o candomblé do campo do exotismo, do folclore, o trata como parte fundamental de nossa herança ancestral. Sua história como Ialorixá, como uma mulher negra, revela o profundo comprometimento com sua ancestralidade, com seus filhos, sua comunidade e seu povo.

Os livros de Mãe Stella "são, pois, um registro da cultura afro-brasileira que possibilitaram à escritora o acesso a espaços antes bem demarcados pela classe hegemônica (branca - masculina - cristã), como a Academia de Letras da Bahia. Acerca disso afirmou a escritora em entrevista: “[...] ninguém nunca pensaria que uma mãe de santo poderia chegar a ocupar este posto. Isso mudou pela nossa luta, mas também por meus livros, porque o que a gente não escreve o tempo leva" (SILVA, 2017, online). Com isto, podemos afirmar que Mãe Stella sabia da importância de se ocupar estes espaços, da garantia de que as vozes das mulheres negras, muitas vezes silenciadas, fossem ouvidas. Com a habilidade de uma verdadeira caçadora Mãe Stella fez isso. Do alto da Roça de São Gonçalo do retiro, Mãe Stella empunhava seu ofá retesado mirando o futuro, o progresso e a prosperidade do povo de santo, do povo negro, dos filhos de Xangô Afonjá. 
A perda de Mãe Stella, em meio a um momento de turbulência e conflitos em sua vida, representou uma perda grande para o povo de Santo, mas como bem sabemos, quem é de Santo não morre, se eterniza na ancestralidade, que é viva e presente, que caminha conosco, nos ensinando o caminho. A força ofá do caçador não se recolheu.

De Obá Biyi a Odé Kayodê as mulheres negras do axé Opô Afonjá continuaram a reinventar suas próprias histórias, continuam a serem autoras de suas existências e narrativas, resistiram e mantiveram de pé o seu povo. As palavras de Mãe Stella ecoam no tempo como flechas disparadas pelo caçador mirando a prosperidade do seu povo. Mãe Stella continua sendo a estrela azul do Afonjá, sua memória é viva.

De Odé Kayodê ao retorno a Xangô Afonjá, com a escolha de Mãe Ana de Xangô Afonjá como sucessora de Mãe Stella, o Ilê Axé Opô Afonjá continua sendo útero que gera, seio que nutre, mão que cuida, coração que afaga e por isso louvamos às nossas ancestrais, nossas grandes! Mojubá Mãe Aninha, Obá Biyi; Mojubá Mãe Stella, Odé Kayodê; Mojubá, Ana de Afonjá. Modupé Orixá, pelas mães que nos acolhem.

\section{Referências bibliográficas}

CAMPOS, Vera Felicidade de Almeida. Mãe Stella de Oxossi: perfil de uma liderança religiosa. Rio de Janeiro: Jorge Zahar Editor, 2003.

FARIA, JULIANA. "Homenagem: Mãe Stela de Oxóssi". Revista África $e$ africanidades, n.5, v.2 - maio/2009.

HAMPATÉ BÂ. “A tradição viva”. In: KI-ZERBO, Joseph (Ed.). História geral da África. v.1: Metodologia e pré-história da África. Brasília: UNESCO, 2010.

PRANDI, Reginaldo. De africano a afro-brasileiro: etnia, identidade, religião. Revista USP, n.46 - junho/agosto 2000.

SANTOS, MARIA STELLA DE AZEVEDO. Meu tempo é agora. São Paulo: Editora Oduduwa, 1993.

SANTOS, Maria Stella de Azevedo; MARTINS, Cléo. E daí aconteceu o encanto. Salvador: Edição das autoras, 1988.

SILVA, Pedro Henrique. "O que a gente não escreve o tempo leva" - Crítica. Literafro - o portal da literatura afro-brasileira; outubro/2017. Disponível em: <http://www.letras.ufmg.br/literafro/autoras/29-critica-de-autores-feminios/301-o-quea-gente-nao-escreve-o-tempo-leva-critica>. Acesso em 02 abr. de 2020.

SODRÉ, Muniz. "Que chegue a alegria / Stella - de Oxossi”. In: SANTANA, Marcos (Org.). Mãe Stella de Oxossi: estrela nossa, a mais singela. Salvador: Pimenta Malagueta Editora, 2014. 
Revista Calundu -Vol.4, N.1, Jan-Jun 2020

\section{Referências - Filmografia}

“Meu tempo é agora”. Direção Ana Ribeiro, 2010. Salvador, 2010. 49min.

“Papo cabeça com Mãe Stella de Oxóssi”. Márcio de Jagun. Salvador, 2018. 30 min.

“Perfil - Mãe Stella de Oxóssi”. TV UFBA. Salvador, 2015. 26 min.

Recebido em: 12/04/2020

Aceito em: 22/04/2020 